\title{
Investigation of Immediate and Delayed Effects of Bilateral Forearm Kinesio-Taping on Maximal Hand Grip Strength in Female Volleyball Players
}

\author{
İzzet Kırkaya (Corresponding author) \\ Department of Coaching Education, School of Physical Education and Sports \\ Yozgat Bozok University, Yozgat, Turkey \\ Tel: 90-555-491-2161Ｅ-mail: izzet.kirkaya@yobu.edu.tr \\ Celil Kaçoğlu \\ Department of Coaching Education, Sport Sciences Faculty \\ Eskişehir Technical University, Eskişehir, Turkey
}

Tel: 90-506-401-7872Ｅ-mail: ckacoglu@eskisehir.edu.tr

Received: November 28, 2020

Accepted: December 23, 2020

Published: December 30, 2020

doi:10.5296/jei.v6i2.18011

URL: https://doi.org/10.5296/jei.v6i2.18011

\begin{abstract}
The aim of this study was to investigate the immediate and delayed effects of the kinesio-taping on the hand grip strength. Six-teen female volleyball players currently competing in Turkey Women's Volleyball $2^{\text {nd }}$ league (age $18.1 \pm 2.3$ years, height $172.9 \pm 7.3$ $\mathrm{cm})$ voluntarily participated in this study. In cross-over research design, all participants participated in a total of 4 different measurements, immediately after kinesio-taping (1), immediately after placebo taping (2), after volleyball training (3), 48h post taping (4). In kinesio-taping, approximately 2-3 cm ends of kinesio-tapes were applied without tension, and the middle region was stretched by approximately $10-15 \%$ in "Y-shape". Hand grip strength measurements were made 4 times on different days that before kinesio-taping, immediately after kinesio-taping, immediately after training and 48 hours after taping with a portable handheld dynamometer. According to the results of the one-way repeated measures ANOVA, the kinesio-taping to forearm didn't elicit any significant changes in hand grip strength over the conditions $(\mathrm{p}>0.05)$. The results of the current study showed that the kinesio-taping in
\end{abstract}


female volleyball players did not have a significant effect on immediate, right after training and 48 hours after taping, compared to placebo taping measurements in dominant and non-dominant maximal hand grip strength.

Keywords: Isometric hand grip strength, Kinesio-taping, Immediate effect, Delayed effect

\section{Introduction}

The hand is of irreplaceable importance for any activity that requires gross or fine motor skills. The main function of the hand is to grip. During the gripping activity, the thumb sometimes involved and sometimes does not. During gripping, an object moves or remains stabilize between the two surfaces of the hand. The grip can be categorized as strong or precise (Nwuga, 1975). It is widely accepted that grip strength provides an objective index of the functional integrity of the upper body (Balogun, Akomolafe, \& Amusa, 1991). Kinesio Taping (KT) method has been developed to support this area during activity. The KT method emerged with the idea of making use of an external component that can aid the function of muscles and other tissues. Thanks to its elastic structure compared to other banding materials, it allows movement without restriction on the range of motion (Thelen, Dauber, \& Stoneman, 2008). KT also positively affect joint motion perception by stimulating the cutaneous mechanoreceptors (Çeliker et al., 2011).

In addition to the results indicating that kinesio-tape (KT) application has no effect on proprioception (Halseth et al., 2004), there are study results (Chen \& Lou, 2008) that demonstrate the movement only increases proprioceptive ability in the middle angles. There are also studies indicating that KT has a negative effect on joint angle perception in $90^{\circ}$ shoulder elevations, and $50^{\circ}$ and $100^{\circ}$ do not have any positive or negative effects (Aarseth et al., 2015).

Some studies have focused on acute effects of KT on muscle strength, while others have reported delayed effects (Murugan et al., 2016).

The purpose of KT taping is to increase the grip strength and improve the functional capacity during daily activities. Donec et al. (2012) reported the positive effects of KT on the normal population. From this point of view, it is aimed to examine whether KT practices have positive aspects on female volleyball players.

\section{Method}

This research has volunteered to 16 female athletes Turkey Women $2^{\text {nd }}$ Volleyball league (age $18.1 \pm 2.3$ years, height $172.9 \pm 7.3 \mathrm{~cm}$, weight $62.6 \pm 7.6 \mathrm{~kg}$, BMI $20.9 \pm 1.5 \mathrm{~kg} / \mathrm{m}^{2}$ ). As a criterion for inclusion in the study, the participant has at least three years of national volleyball competition experience with no neuromuscular disease, no history of ligament, tendon, connective tissue, neuromuscular injury, upper extremity soft tissue or bone fracture in the wrist and in the article, female individuals between the ages of 18-24, who used their right hand, were included in the study. Those with irritation or open wounds in the upper skin in the area where the kinesio-tape is applied, those who have metabolic, cardiac, pulmonary diseases, those who use drugs that affect heart rate or blood pressure, those who have 
systemic, neuroplastic, inflammatory conditions, structural back anomalies and any such health problems were not included in this study. This research has been approved by the Ethics Committee of Non-Interventional Clinical Research Ethics Committee of Eskişehir Osmangazi University (Number: 25403353-050.99-E.121522, Decision no: 31, Decision date: 06.11.2018).

All participants confirmed that they were informed by signing the pre-study information form and that they voluntarily participated in this study. All the processes of the research were carried out in accordance with the Helsinki Declaration, Ethical Principles of Human Research. After obtaining the ethics committee approval for the research, all participants participated in the trial and promotion session, where they were applied to the tests and applications. About 10 days after the trial and promotion session, the tests of the study started. Measurements were made at the same time of the day and by the same expert researcher. In this research using cross-over research design, all participants participated in a total of 3 different measurements, immediately after placebo taping (1), immediately after kinesio-taping (2), after routine volleyball training (3), and $48 \mathrm{~h}$ post taping (4). Measurements were taken at least 72 hours apart. They were told not to consume caffeinated or alcoholic beverages, take drugs, and continue their routine nutrition and hydration within 24 hours before the test days.

\subsection{Taping Technique}

Kinesio ${ }^{\circledR}$ Tex Gold (Kinesio USA, Albuquerque, NM) cotton, water resistant and latex-free elastic band with a width of $5 \mathrm{~cm}$ was used for the taping technique. Before the taping, the application area was cleaned with alcohol and dried. Taping procedure is applied to the wrist flexor muscles in the right and left forearms, while individuals are in a standing position. Kase et al. (2003) the protocol proposed for elbow medial epicondylitis was implemented. 2-3 cm ends of kinesio-tapes were applied without tension, and the middle region was stretched by In KT, approximately approximately 10-15\%. The tape was cut in "Y-shape" form according to the length of the participant's forearm region before taping. Before taping, individuals were asked to bring the wrist and elbow joint on the side where taping was applied to bring as much extension as possible and forearm to supination. The single end of the "Y-shape" tape was applied on the skin, starting from the insertion region of the flexor muscles at the anterior distal of the forearm, and the double end ending approximately $2 \mathrm{~cm}$ inferior part of the medial epicondyle of the humerus in the origo region. In placebo taping, the kinesio tape cut in the form of "I-shape" of approximately $10 \mathrm{~cm}$ was applied tensionlessly perpendicular to the direction of the forearm flexor muscles to the approximately $5 \mathrm{~cm}$ inferior part of the medial epicondyle (Figure 1). If they feel uncomfortable for any reason or need removal, they are said to be free to remove, and these participants were excluded from the study. 

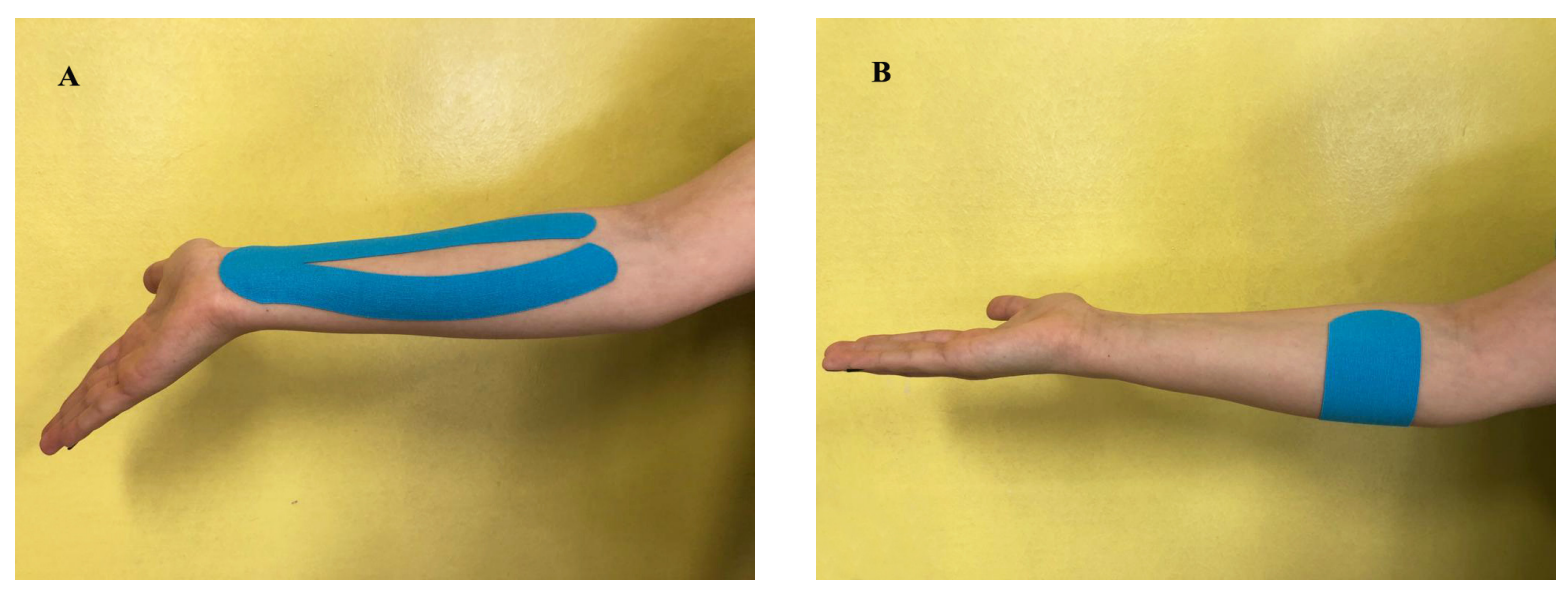

Figure 1. "Y-shape" Kinesio tape application A) experimental application, B) placebo taping

\subsection{Hand Grip Strength Tests}

Hand grip strength measurements were assessed to 4 times on different days before KT, immediately after KT, immediately after training and 48 hours after taping. Hand grip strength is assessed with a portable hand grip strength gauge dynamometer (Takei Ltd.). The participants were asked to squeeze the grip of the dynamometer's arms as strongly as possible for 5 seconds. Measurements were made in standing position, shoulder approximately $20^{\circ}-30^{\circ}$ abduction, no rotation, forearm in neutral position, elbow and wrist in $0^{\circ}$ extension. During the measurements, participants were verbally encouraged. Measurements that were measured twice at one minute intervals were recorded for great value analysis (Chang et al., 2010).

\subsection{Statistical Analysis}

A one-way repeated measures ANOVA was conducted to determine whether there was a statistically significant difference in hand grip strength over the 4 different conditions. There were no outliers and the data was normally distributed for each condition, as assessed by Shapiro-Wilk test $(p>.05)$. Mauchly's Test of Sphericity indicated that the assumption of sphericity had not been violated for dominant and non-dominant hand grip strength $\chi^{2}(5)=$ $7.904, p=.165 ; \chi^{2}(5)=5.691, p=.341$, respectively.

\section{Results}

According to the analysis the KT to forearm did not elicit any statistically significant changes in hand grip strength over the conditions, $\mathrm{F}(3,17)=0.847, \mathrm{p}=0.480$, partial $\eta^{2}=0.086, \mathrm{~F}(3$, $27)=1.441, p=0.253$, partial $\eta^{2}=0.138$, respectively. Hand grip strength values little changed from $30.2 \pm 1.5$ and $27.4 \pm 2.4 \mathrm{~kg}$ at control condition to $30.4 \pm 3.5$ and $28.9 \pm 4.0 \mathrm{~kg}$ immediately after the taping to $30.6 \pm 3.1$ and $27.9 \pm 2.2 \mathrm{~kg} 48$ hour after taping to $31.1 \pm 2.6$ and $28.6 \pm 3.3 \mathrm{~kg}$, respectively (Figure 2). 


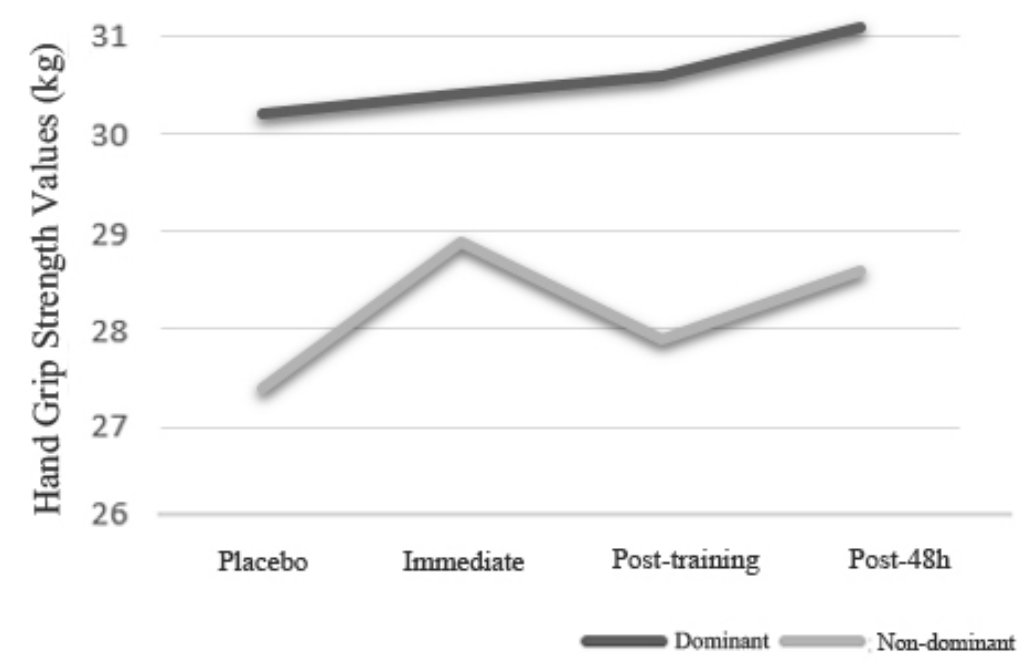

Figure 2. Hand grip strength changes after KT on forearm flexor muscle group

\section{Discussion}

The results of this study showed that the application of kinesio-tape in female volleyball players did not have a significant effect on immediate, right after training and 48 hours after taping, compared to tapeless control measurements in dominant and non-dominant maximal hand grip strength.

When the literature is examined, there are studies that KT has a positive effect on strength values as well as studies that show that hand grip does not increase strength. According to these studies, the difference in KT applications explains the diversity in the results.

Fu et al. (2008) stated that KT has no effect on isokinetic knee strength immediately and after 12 hours. Fratocchi et al. (2013) stated that kinesio-taping has positive effects on concentric and eccentric biceps muscle strength in immediate and healthy individuals. In a study investigating the acute effect of KT applied to the dominant side forearm extensor muscles in healthy individuals on hand grip strength, it was revealed that the hand grip strength increased according to the pre-test, and that there was no increase in the non-elastic banding group (J. Y. Kim \& S. Y. Kim, 2016). Brychcy and Pawlak (2019) stated that KT application did not increase hand grip strength according to measurements made after KT applied to forearm muscles and 3 hours after application in healthy individuals. While there was an increase in hand grip strength of non-kinesio taping (downward Y-taping) applied to forearm muscles in healthy female subjects 24 hours after taping, no increase was observed in the upward Y taping and control group. Especially in healthy sedentary individuals, KT has positive contributions to grip strength. Donec et al. (2012) observed an increase in maximal hand grip strength 30 minutes and 1 hour after kinesio taping applied bilaterally to the forearm muscles. Right after I-shape KT application to the forearm extensor muscles, 30, 60 and 120 minutes after, they reported that KT applied to the shoulder and forearm caused an increase in hand grip strength. According to the results of the measurements performed 30, 
60, 90, 120 minutes after I-shape KT application to the forearm flexor and extensor muscles in healthy individuals, it was determined that the 30 minute strength increase rate was the highest $(10.8 \%)$ in men. This rate has gradually decreased afterwards. In females, it was observed that the increase in strength of 90 minutes was maximum (23.9\%) (Mohammadi et al., 2014). In a study applied to forearm muscles in healthy individuals, they stated that Y-shape kinesio taping had positive effects on hand grip strength (Cha et al., 2016). In a study investigating the effect of the application direction of kinesio taping on hand grip strength in healthy female individuals, it was revealed that the taping from the bottom up (insersio to origo) was not effective in the perception of hand grip strength (Hosseini et al., 2019). Similar results have been found in that study.

Despite the positive and negative studies given above, the clinical usefulness of KT still remains unclear. As a result of the findings, positive effects of KT applications on hand grip strength could not be reached. Since KT application is not effective on hand grip strength, it can be said that this application provides only psychological relief.

\section{Acknowledgements}

We would like to express our sincere gratitude to our Bachelor student Yaren Gürsöz and Tepebasi Municipality Sports Club Women's Volleyball Team Coaches Fatma Yağcı Çimenli and Özkan Çimenli for their invaluable supports in this study.

\section{References}

Aarseth, L. M., Suprak, D. N., Chalmers, G. R., Lyon, L., \& Dahlquist, D. T. (2015). Kinesio tape and shoulder-joint position sense. Journal of Athletic Training, 50(8), 785-791. https://doi.org/10.4085/1062-6050-50.7.03

Balogun, J. A., Akomolafe, C. T., \& Amusa, L. O. (1991). Grip strength: Effects of testing posture and elbow position. Archives of Physical Medicine and Rehabilitation, 72(5), 280-283. Retrieved from https://www.archives-pmr.org/article/0003-9993(91)90241-A/pdf

Brychcy, A., \& Pawlak, M. (2019). Kinesio Taping does not alter the blood flow in the area of application-A pilot study. Trends in Sport Sciences, 26(4), 171-176. https://doi.org/ 10.23829/TSS.2019.26.4-5

Çeliker, R., Güven, Z., Aydoğ, T., Bağiş, S., Atalay, A., Çağlar Yağci, H., \& Korkmaz, N. (2011). Kinezyolojik Bantlama Tekniği ve Uygulama Alanları. Fiziksel Tup ve Rehabilitasyon Bilimleri Dergisi, 57, 225-235. https://doi.org/10.4274/tftr.46548

Cha, H. G., Kim, M. K., \& Shin, Y. J. (2016). Immediate effects of forearm elastic and nonelastic taping on wrist flexor muscle and grip strength of normal adults. Journal of Physical Therapy Science, 28(10), 2769-2771. https://doi.org/10.1589/jpts.28.2769

Chang, H. Y., Chou, K. Y., Lin, J. J., Lin, C. F., \& Wang, C. H. (2010). Immediate effect of forearm Kinesio taping on maximal grip strength and force sense in healthy collegiate athletes. Physical Therapy in Sport, 11(4), 122-127. https://doi.org/10.1016/j.ptsp.2010. 06.007 
Chen, C. Y., \& Lou, M. Y. (2008). Effects of the application of Kinesio-tape and traditional tape on motor perception. Br. J. Sports Med., 42, 513-4. Retrieved from https://kinesio-production.s3.amazonaws.com/uploads/material_document/2003-6.pdf

Donec, V., Varžaitytė, L., \& Kriščiūnas, A. (2012). The effect of Kinesio Taping on maximal grip force and key pinch force. Polish Annals of Medicine, 19(2), 98-105. https://doi.org/ 10.1016/j.poamed.2012.08.004

Fratocchi, G., Di Mattia, F., Rossi, R., Mangone, M., Santilli, V., \& Paoloni, M. (2013). Influence of Kinesio Taping applied over biceps brachii on isokinetic elbow peak torque. A placebo controlled study in a population of young healthy subjects. Journal of Science and Medicine in Sport, 16(3), 245-249. https://doi.org/10.1016/j.jsams.2012.06.003

Fu, T. C., Wong, A. M., Pei, Y. C., Wu, K. P., Chou, S. W., \& Lin, Y. C. (2008). Effect of Kinesio taping on muscle strength in athletes-A pilot study. Journal of Science and Medicine in Sport, 11(2), 198-201. https://doi.org/10.1016/j.jsams.2007.02.011

Halseth, T., McChesney, J. W., DeBeliso, M., Vaughn, R., \& Lien, J. (2004). The effects of kinesio $^{\text {TM }}$ taping on proprioception at the ankle. Journal of Sports Science \& Medicine, 3(1), 1-7. Retrieved from https://www.ncbi.nlm.nih.gov/pmc/articles/PMC3896108

Hosseini, S. M., Rezaiian, F., Kalantari, K. K., Tabatabaei, S. M., \& Dehno, N. S. (2015). Effects of forearm kinesiotaping on maximum power grip and endurance in healthy females. Rehabilitation Medicine, 3(4). https://doi.org/10.22037/R.M.V3I4.7842

Kase, K., Wallis, J., \& Kase, T. (2003). Clinical therapeutic applications of the Kinesio taping method (Vol. 2). Albuquerque, NM: Kinesio Taping Assoc.

Kim, J. Y., \& Kim, S. Y. (2016). Effects of kinesio tape compared with non-elastic tape on hand grip strength. Journal of Physical Therapy Science, 28(5), 1565-1568. https://doi.org/ $10.1589 /$ jpts. 28.1565

Mohammadi, H. K., Kalantari, K. K., Naeimi, S. S., Pouretezad, M., Shokri, E., Tafazoli, M., ... \& Kardooni, L. (2014). Immediate and delayed effects of forearm kinesio taping on grip strength. Iranian Red Crescent Medical Journal, 16(8), e19797. https://doi.org/ 10.5812/ircmj. 19797

Murugan, S., Shruti, P., Tejal, P., \& Charul, P. (2016). Facilitatory Effects of Kinesio Taping on Forearm Extensors in Improving Hand Grip and Pinch Grip Strength. Sch. Acad. J. Biosci, 4(6), 478-482. https://doi.org/10.21276/sajb.2016.4.6.5

Nwuga, V. C. (1975). Grip strength and grip endurance in physical therapy students. Archives of Physical Medicine and Rehabilitation, 56(7), 297. Retrieved from https://pubmed.ncbi.nlm. nih.gov/1147747/

Thelen, M. D., Dauber, J. A., \& Stoneman, P. D. (2008). The clinical efficacy of kinesio tape for shoulder pain: A randomized, double-blinded, clinical trial. Journal of Orthopaedic \& Sports Physical Therapy, 38(7), 389-395. https://doi.org/10.2519/jospt.2008.2791 


\section{Copyright Disclaimer}

Copyright for this article is retained by the author(s), with first publication rights granted to the journal.

This is an open-access article distributed under the terms and conditions of the Creative Commons Attribution license (http://creativecommons.org/licenses/by/3.0/). 